after the restoration of all function the fracture may look very much as it did at first.

Let patients be told in every instance now that the "new photography" is no measure of the "cure"; that the setting of a fracture is not what, apparently, they have always thought it-a piece of cabinet work-but that from the very nature of things, bones buried in soft parts, the necessary manipulations to fit jagged ends together are impossible without operation, though the apparent maladaptation of the bones indicates neither a failure to bring about the conditions for sound union, nor argues loss of function hereafter.

The sooner, by one way or the other, the public is instructed in the uncertain indications that skiagraphy gives, the sooner will lawyers learn that it is not a reliable witness-less so, indeed, than ordinary photography; and the less ready will a certain class of them-well known to our profession-be eager to seize on a skiagraph to "make a case" "and use it as a motive to urge on a weak but greedy client to bring an undeserved charge of malpractice against his doctor.

So new a field did skiagraphy open up, that I fear we are all to blame for being too sanguine as to the opportunities it would offer for certainty in the diagnosis of fracture; and the public has caught - shall I say been educated up to catching? - the infection. The too hasty and too fervent trust put in a new method before time had allowed of its thorough investigation is now recoiling on our own heads.

Instead of narrating cases where mistakes have been 'made either in taking the skiagraph, or misinterpreting it, I have preferred to indicate its gross uncertainties; though as new discoveries are made these will be Jess frequent; but until the use of the $x$ rays can be raised above the level of empiricism, we are forced to be guarded in our judgment of what they show ; and for the present, at least, a practitioner who has not considerable experience of skiagraphy should be very shy of using it to test his own work, or without skilled aid of thinking to successfully rebut a charge brought against him on the strength of a skiagraph produced by a patient.

In skiagraphy "things are not what they seem" very often; and, when it is called for for medico-legal purposes, only a skilled operator's picture should be used, and its iinterpretation be left to an expert who is a professional man and at least well acquainted with $x$-ray work. The actual reading of the picture may be, and is in many cases, easy; but in charges of malpractice it is not the beauty of the bone scar that should determine the rights of the case-though this is the thing that is being at present ingeniously waved before the eyes of juries-but the relationship, if any, that the skiagraphic appearances bear to the clinical result produced by the treatment. It is this last which neither lawyer nor photographer can estimate, but a professional witness only.

Skiagraphy cannot stand alone even for the everyday practice of diagnosis, still less can its uncorroborated testimony be safely invoked for defence or attack in a court of law. With the many examples before us of its misuse in this latter capacity, we may well learn to be cautious in the employment of such a sharp-edged tool, which, injudiciously handled, may suddenly turn and inflict a life-long injury. ${ }^{6}$

\section{NOTES AND REFERENCES.}

1 The demonstration of this given by Mr. Shenton, the radiographer to Guy's Hospital, before the Clinical Society of London in February of this year will be in the memory of many ${ }^{2}$ The apparent paradox of ill-adaptation and yet no shortening in "oblique" fractures I have discussed elsewhere. BRITISH MEDICAL JOURNAL, roo, vol. i, p.945. 3 This error is well exposed by Mr. Muirhead Little in the BRITISH MEDICAL JoURNAL, r899, vol, i, p. 1209. See also an editorial on the discrepancy between the $x$ attention to the erroneous interpretation as well as appearances of hip skiagraphs. 4 Dr. E. A. Tracy, Journal of the American Medical A8sociation, November $6 \mathrm{th}$, 1897. 5 Dr. F. W. Ross quotes a similar case in France where the evidence of skiagraphy was upheld in the law courts in favour of the plaintiff. American $X$-Ray Journal, January, 1899. 6 Chapter XVII by Dr. Codman in Scudder's Treatment of Fractures, and edition, 19or, goes fully into the question of the relation of the Roentgen rays to fractures, both from the point of view of practice and of medico-legal possibilities.

The Sanitary Inspectors' Examination Board. - We are informed that at the the examination for sanitary inspectors hela by this Board in May, 14 candidates passed, of these 9 were women. The number of candidates who presented themselves for examination is not stated.

\section{A CASE OF OBLIQUE FRACTURE OF TIBIA AND FIBULA WITH SKIAGRAPHS SHOWING REPAIR.}

\author{
With Special Plate.
}

BY BENJAMIN DUKE, M.D., M.R.C.S., Clapham Oommon, S.W.

THE two skiagraphs from a case of oblique fracture of the tibia and fibula, whioh are presented on the Special Plate, seem to me of great interest.

The patient was a stout, heavily-built girl, aged 18 . While skating with roller skates on a rink she fell, doubling her leg under her. She states that she was able to stand on the leg afterwards. Fractured fibula was diagnosed by two surgeons, and the leg placed on a splint. I saw her later on, and found the leg in a good position. On passing my finger down the shaft of the tibia I could feel no break in continuity, or swelling, or shortening of the limb, and agreed with the diagnosis of simple fracture of the fibula, which could be felt. About a week after, it being necessary to move the patient home, the leg was placed in a plaster-of-paris splint. Even then there was no evidence of fractured tibia. In a month's time the casing was removed and massage commenced, with later on gentle exercise.

On the eightieth day the skiagraph (Fig. I) was taken. Imagine my horror on first seeing it, with the tibia broken and ends widely apart! I felt the patient would have been fully justified in describing the treatment as an utter failure; but advised continuation of gentle exercise, persuaded that all would be well. This opinion the skiagraph (Fig. 2) taken eighteen months after the accident has fully justified. The girl can now run, dance, play tennis, or walk any distance, and there is no lameness.

The case is of great interest to the surgeon for the following reasons: First, the diagnosis was not easy, simple as it looks in the skiagtraph taken eighty days after the accident. Secondly, the result is far better than could have been anticipated. Thirdly, supposing the patient, with the usual stiffiness about the ankle-joint and lameness due to adhesions, etc., had appealed with this picture in hand to a legal tribunal, what verdict would the jury have returned? Would it have been in the surgeon's favour? I say unquestionably "No." But could he have produced the second skiagraph taken eighteen months afterwards I think "Yes."

The skiagraphs were taken by $\mathrm{Mr}$. Glew, 156, Clapham Road, S.W.

National Society for EMPLOYMENT OF EPILEPTICS.-The eighth annual meeting was held on June 3 rd at the offices of the Society, 12, Buckingham Street, Strand, under the presidency of Mr. E. Montefiore Micholls, Chairman of the Executive Committee. In the course of the past year considerable progress has been made at the Chalfont colony, the number of patients, in consequence of the opening of the new homes, having increased to 136 . The applications had, however, multiplied so rapidly that the need for further extension is greater now than ever before. As the result of the treatment received by them at Chalfont many ex-colonists, both men and women, are now supporting themselves by their own exertions in the outside world. For the majority of cases, however, especially those in whom the disease is of long standing, the colony must be regarded as a permanent home, where they are enabled to enjoy a life incomparably happier and more useful than would be open to them in their own homes. A convalescent home for twenty-four male patients is now in course of erection, and an additional farm, comprising 75 acres, adjoining the existing property of the Society, is about to be acquired. A comparison of the expenditure of the Society for the years 1895 and 1900 shows that although the number of patients has increased fivefold, the cost of maintenance per patient has diminished by more than 50 per cent., a result which is to be attributed to the economical advantages arising, under the colony system, from dealing with increased numbers. This fact, the Committee urge, may justly commend itself to the consideration of the charitable public as an additional reason for the further extension of the acoommodation at the colony. 

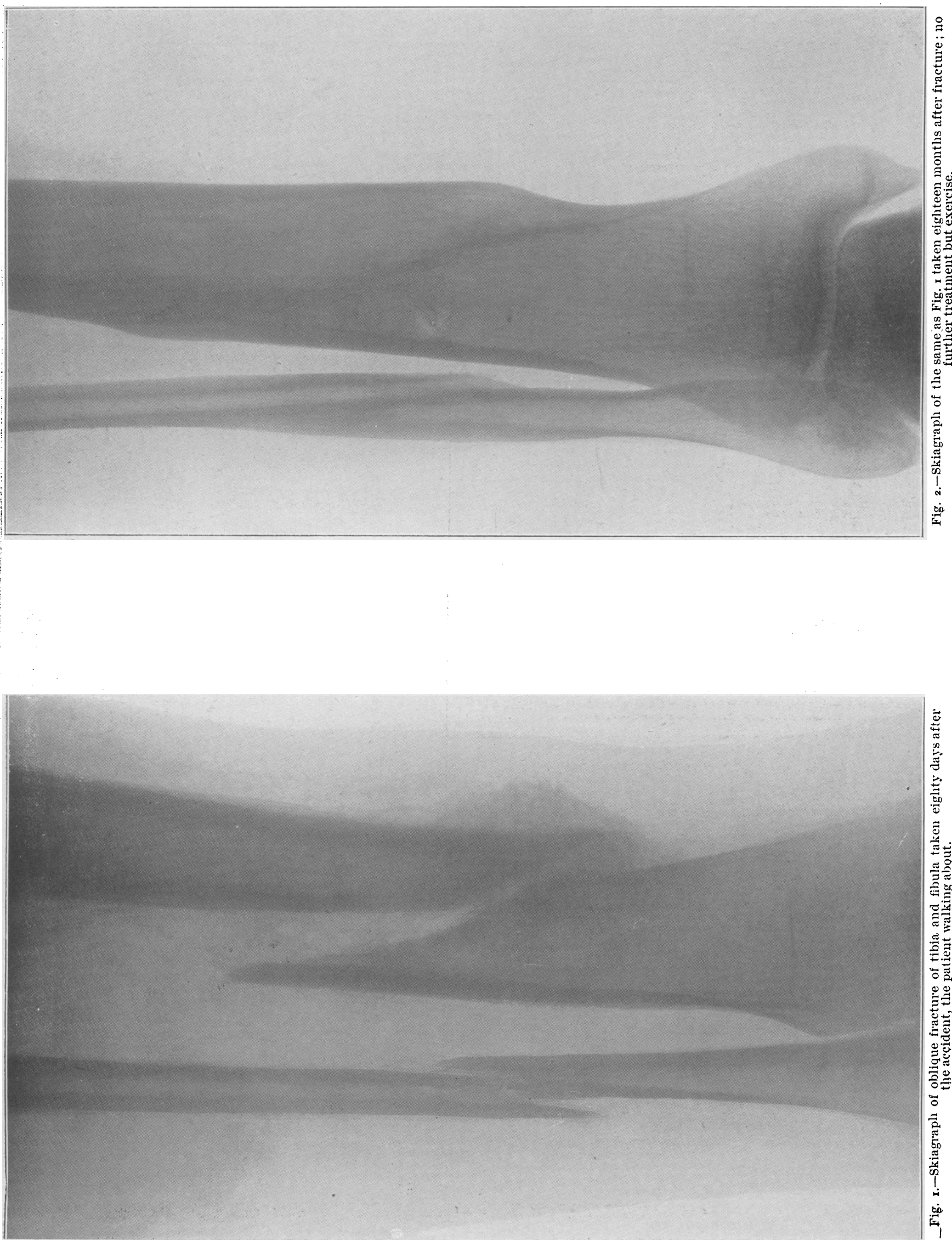

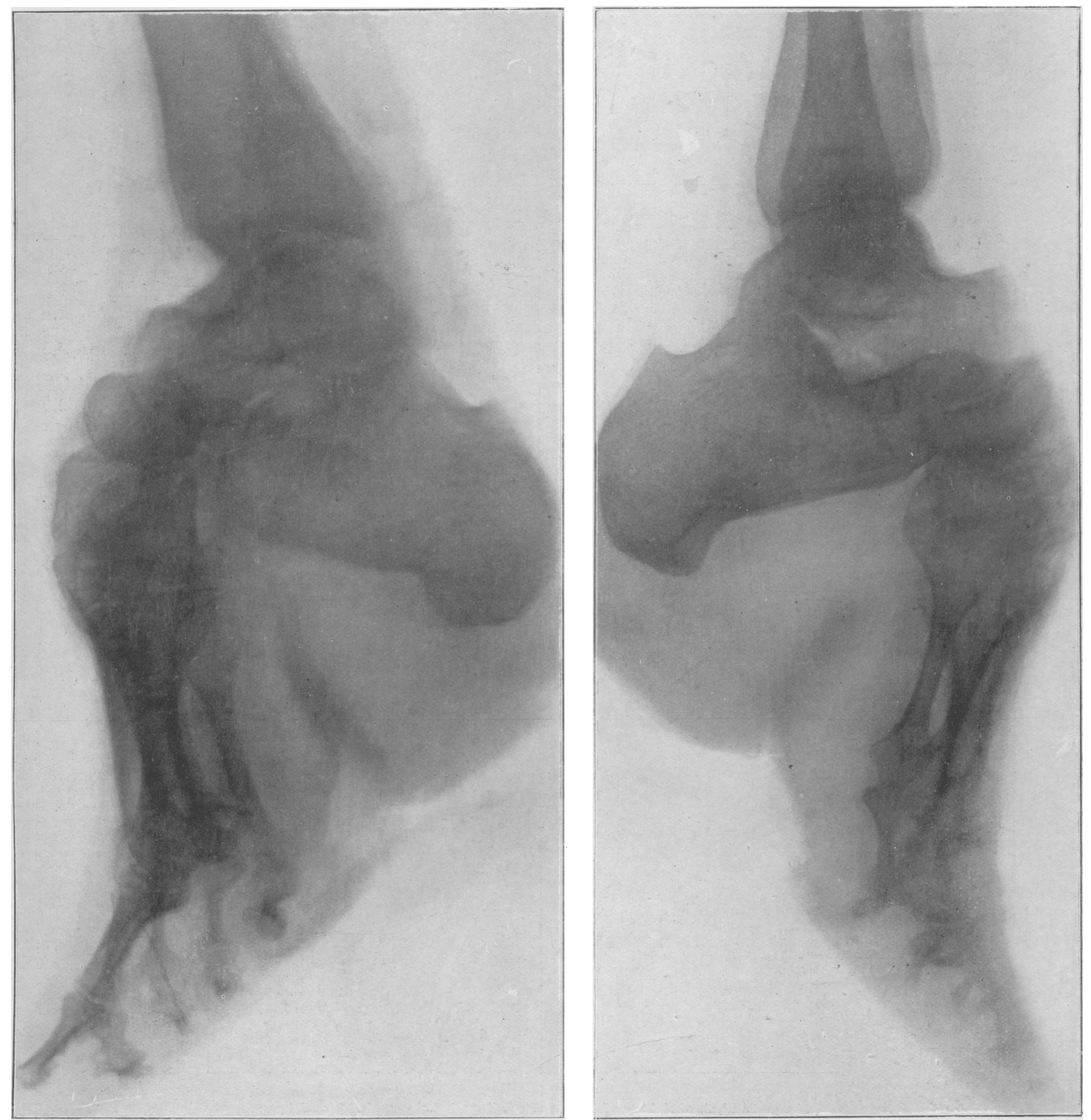

Dr. J. Duncan Thomson, of Hankow, China, has sent the accompanying skiagraphs and descriptions of the changes occurring in the deformity of the Chinese lady's foot:

The first is that of a small foot, taken with the inner (tibial) side next the plate. The second is that of a small foot, taken with the outer

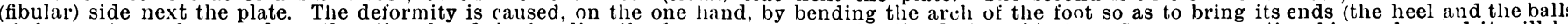

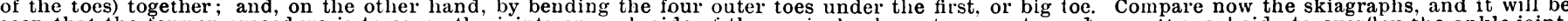

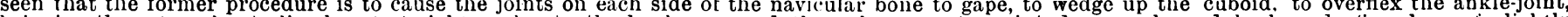

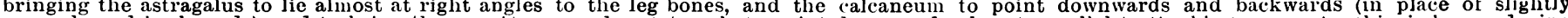

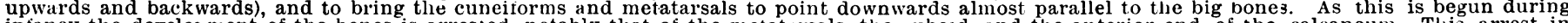

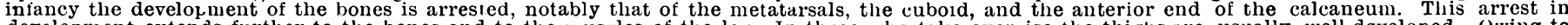

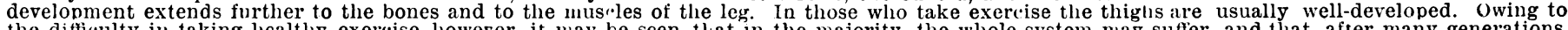

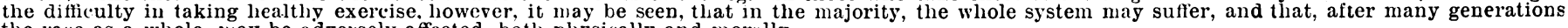
the race as a whole, nay be adversely affected, both physically and morally. 